\title{
Investigation of Electromagnetic Wave Absorber Based on Carbon Fiber Reinforced Aerated Concrete Using Time-Domain Method
}

\author{
A. Laukaitis ${ }^{a, *}$, M. Sinica ${ }^{a}$, S. BalevičIus ${ }^{b, c}$ \\ AND B. LEVITAS ${ }^{d}$ \\ ${ }^{a}$ Institute of Thermal Insulation, Vilnius Gediminas Technical University \\ 28 Linkmenu̧ str., Vilnius, Lithuania \\ ${ }^{b}$ Semiconductor Physics Institute \\ A. Goštauto 11, Vilnius, Lithuania \\ ${ }^{c}$ Vilnius Gediminas Technical University \\ Saulètekio 11, Vilnius, Lithuania \\ ${ }^{d}$ Geozondas LTD, 16 Shevchenko str., LT-2009, Vilnius, Lithuania \\ The electromagnetic wave absorbers prepared from autoclaved aerated \\ concrete containing carbon fibers as additions in the shape of slabs with pyra- \\ mids cut on one plane of these slabs were tested using dc microwave source \\ and the time-domain method. It was demonstrated that autoclaved aerated \\ concrete allows one to fabricate electromagnetic wave absorbers which have \\ a reflection coefficient up to $-30 \mathrm{~dB}$ in the frequency range from $2 \mathrm{GHz}$ to \\ $18 \mathrm{GHz}$. \\ PACS numbers: 41.20.Jb, 81.05.Uw
}

\section{Introduction}

The addition of carbon fibers to autoclaved aerated concrete (AAC) gives it a new property - the ability to absorb electromagnetic waves [1]. This additive also positively affects some other characteristics of AAC by increasing its mass plastic strength, the compression and flexural strength, as well as the durability of aerated concrete products [2]. The additive considered does not affect phase composition of calcium-silicates-hydrate, the coating of the fibers ensures firm bond to aerated concrete, thus increasing its strength and durability. In general, the effectiveness of AAC as electromagnetic waves absorber is tested using continuous waves of fixed frequency. In this paper we present the new results obtained using time domain method (TDM) when a wide-band pulse propagating in the free space impinges

*corresponding author; e-mail: antanas.laukaitis@termo.vgtu.lt 
against AAC. Changing the density of the carbon fibres it is possible to tune the absorber characteristics, for this reason the AAC can be used as a model for study of various non-homogeneous environments, such as high resistivity semiconductors containing low resistance inclusions.

\section{Experimental}

The radio frequency absorbing material was made from quarry quartz sand, Portland cement of CEM I 42,5 R grade, calcite ground lime, Al powder as a pore former and carbon fibers. The mineralogical composition of the clinker was $63.63 \%, 10.55 \%, 6.47 \%$, and $12.22 \%$ for $3 \mathrm{CaO} \cdot \mathrm{SiO}_{2}, 2 \mathrm{CaO} \cdot \mathrm{SiO}_{2}, 3 \mathrm{CaO} \cdot \mathrm{Al}_{2} \mathrm{O}_{3}$, and $\mathrm{Al}_{2} \mathrm{O}_{3} \cdot \mathrm{Fe}_{2} \mathrm{O}_{3}$, respectively. Carbon fibers of non-ideal cylindrical form having $10 \mathrm{~cm}$ length and $0.4-1 \mu \mathrm{m}$ cavities on the surface were used as inclusions for electromagnetic wave absorbing. The diameter of the fibers varied from 4.6 to $7.7 \mu \mathrm{m}$, its tensile strength being $450 \mathrm{~N} / \mathrm{mm}^{2}$.

Test samples were made in the shape of slabs [3], one side of which had mechanically cut out truncated pyramids. Two sizes of slabs, with dimensions $440 \times 440 \times 80 \mathrm{~mm}$ and $440 \times 440 \times 140 \mathrm{~mm}$ were produced. The base and height of the pyramids were $35 \mathrm{~mm}$ and $45 \mathrm{~mm}$ for the $440 \times 440 \times 80 \mathrm{~mm}$ dimension slab, respectively. The base of a single pyramid of this slab was $40 \mathrm{~mm}$. The $440 \times 440 \times 140 \mathrm{~mm}$ dimension slab had pyramids with $60 \mathrm{~mm}$ base and $80 \mathrm{~mm}$ height. The base of a single pyramid in this case was $57 \mathrm{~mm}$. The pyramids were cut in planes parallel to the base plane producing a $10 \times 10 \mathrm{~mm}$ area on the top of these pyramids.

In the TDM, the attenuation of the absorber was measured by using ps duration electrical pulses generated at a $100 \mathrm{kHz}$ repetition rate. The frequency range of the measurement $(0.85-18 \mathrm{GHz})$ was limited by the band width of the receiving antenna. The experimental setup used for these measurements operated in the following way. The electrical pulses, having amplitude $30 \mathrm{~V}$ and duration $30 \mathrm{ps}$, were generated by means of a short pulse generator containing a pulsesharpening circuit based on a backward diode. The pulses were fed through a directional coupler to a transmitting antenna and input of the sampling head of the sampling converter. After reflection from the object under test, the transmitted pulse was recordered by a receiving antenna and transmitted to the input of the sampling head of the sampling converter. The spectrum of the pulse was calculated by using the Fourier transform. In order to obtain the reflection coefficient, the spectrum of the signal reflected from the investigated object and the spectrum of the signal reflected from the metallic plate with the same dimensions as the slab was used.

\section{Results and discussion}

Primarily the investigation of the slab's ability to absorb continuous electromagnetic irradiation was made. It was obtained that $440 \times 440 \times 80 \mathrm{~mm}$ slab 
absorption of $0.8-10 \mathrm{~cm}$ waves is $-20 \mathrm{~dB}$. However, in the $10-15 \mathrm{~cm}$ wavelength range, the absorption ability decreases up to $-15 \mathrm{~dB}$. The $440 \times 440 \times 140 \mathrm{~mm}$ slab exhibited better absorption characteristics in the $0.8-15 \mathrm{~cm}$ wavelength range (not less than $-20 \mathrm{~dB}$ ). Stronger absorption of $0.8-3 \mathrm{~mm}$ waves $(-30 \mathrm{~dB})$ is a result of the thicker slab base $(60 \mathrm{~mm})$, while the increase in absorption of $3-15 \mathrm{~cm}$ wavelength waves is due to the increase in pyramid height.

The reflection coefficient $(A)$ of slabs having different shapes at one surface was investigated using TDM. Four types of slabs were investigated: slabs with large (80 mm height) pyramids, slabs with small (45 mm height) pyramids, uniform slabs and slabs having small riffles on one surface. Figure 1a demonstrates that slabs

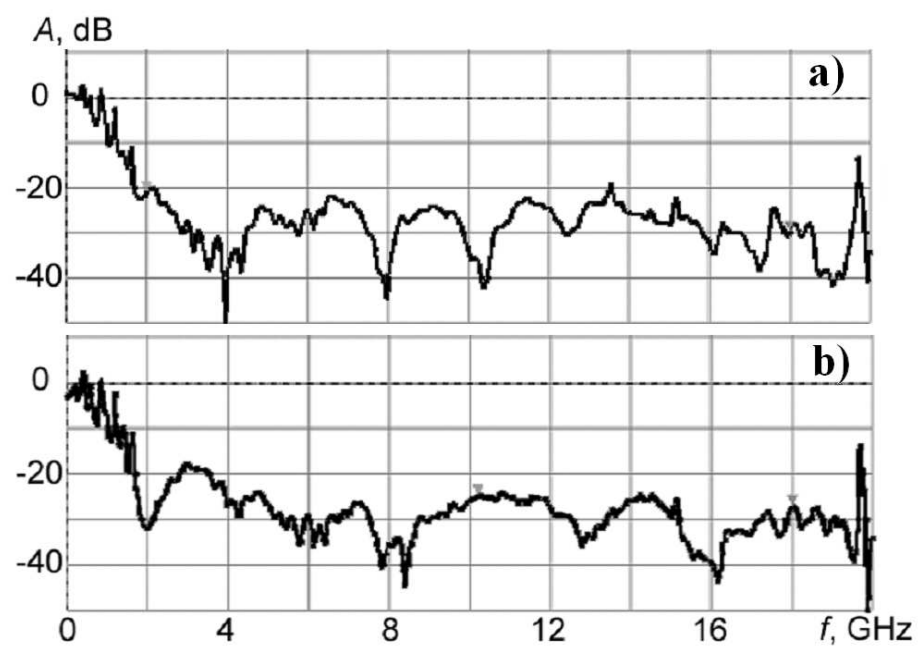

Fig. 1. Reflection coefficient vs. frequency: (a) $440 \times 440 \times 140 \mathrm{~mm}$ slab; $60 \mathrm{~mm}$ base and $80 \mathrm{~mm}$ height pyramids (large pyramids); (b) $440 \times 440 \times 80 \mathrm{~mm}$ slab; $35 \mathrm{~mm}$ base and $45 \mathrm{~mm}$ height pyramids (small pyramids).

with carbon fibres additions having large pyramids exhibit reflection coefficients ranging from $-21 \mathrm{~dB}$ to $-30 \mathrm{~dB}$ at frequencies ranging from $2 \mathrm{GHz}$ to $18 \mathrm{GHz}$. Slabs with smaller pyramids, in this frequency range, showed smaller absorption. In this case, the reflection coefficient was $-18 \mathrm{~dB}$ and $-27 \mathrm{~dB}$, respectively (Fig. 1b). The reflection coefficient of uniform slabs without carbon fibres inclusions (see Fig. 2a,b) was found to be much smaller, $-11.15 \mathrm{~dB}$ and $-13.63 \mathrm{~dB}$ for $2 \mathrm{GHz}$ and $18 \mathrm{GHz}$, respectively. Small riffles on one surface of the slab slightly increased the absorption up to $-17 \mathrm{~dB}$. Riffles also induced "waving" of the absorption coefficient vs. frequency dependence. This effect is the result of wave reflection from pyramids or riffles and for this reason the "wavelength" and "amplitude" of the waving correlates with the dimensions and shape of these non-homogeneous slabs. 


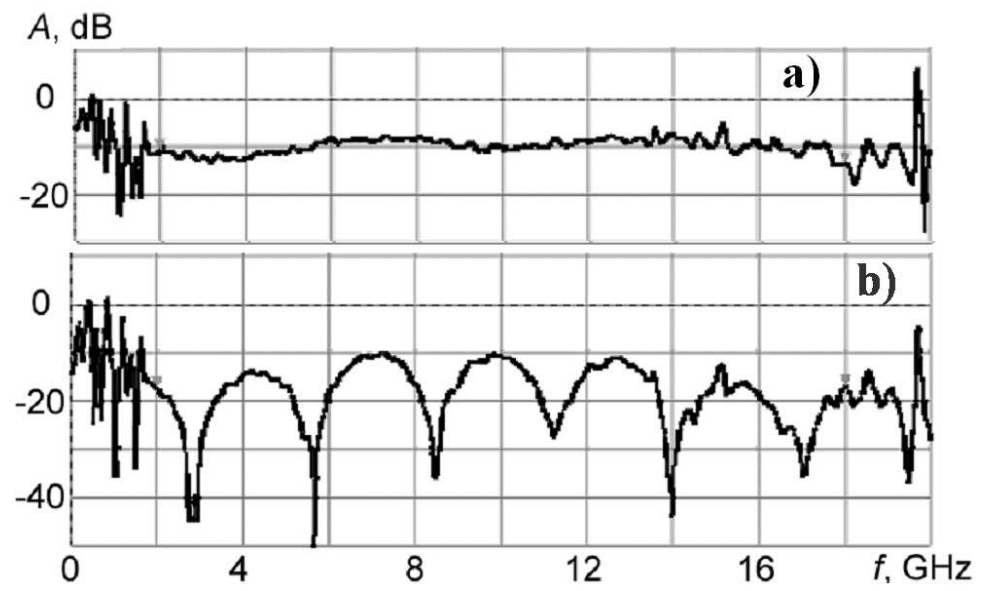

Fig. 2. Reflection coefficient of AAC without carbon fibres additions: (a) slab without riffles, (b) slab with riffles.

In conclusion, the ability of AAC to absorb electromagnetic wave in the frequency range from $2 \mathrm{GHz}$ to $18 \mathrm{GHz}$ strongly depends on the presence or absence of carbon fibres and the shaping of one surface of the slabs.

\section{Acknowledgments}

The work was supported by the Lithuanian Science and Studies Foundation contract No. B-21.

\section{References}

[1] J.-M. Chiou, Q. Zheng, D.D. L. Chung, Composites 20, 379 (1989).

[2] T.-J. Kim, C.-K. Park, Cem. Concr. Res. 28, 955 (1998).

[3] A.A. Laukaitis, A.E. Bichovskis, M.S. Sinica, N.K. Povilavičienè, I.V. Piragis, Patent SU No. 1168417. 